Tema: Solidificação / Lingotamento

\title{
EVOLUÇÃO NO SISTEMA DE PARTIDA COM DISTRIBUIDORES A FRIO NA ARCELORMITTAL TUBARAO*
}

\section{Resumo}

\author{
Alexandre de Aparecida Morais ${ }^{1}$ \\ Jadir Dadalto ${ }^{2}$ \\ José Carlos de Pontes Junior ${ }^{3}$ \\ Sandro de Souza Santos ${ }^{4}$ \\ Jorge Luiz Maioli ${ }^{5}$ \\ Roginério Ferreira de Souza ${ }^{6}$
}

No processo de lingotamento contínuo a secagem e o pré-aquecimento do refratário do distribuidor são de fundamental importância. Estes são realizados visando: reduzir a perda de calor do aço líquido, reduzir as bolhas nas primeiras placas, evitar respingos de aço (reações) ocasionados pela umidade e prevenir a degradação refratário por choque térmico. Para aços planos, os sistemas para promover a secagem e pré-aquecimento podem ser do tipo a "quente" (mais usual) ou a "frio". É denominado "partida a quente" quando se realiza a secagem e o pré-aquecimento; e de "partida a frio", quando apenas a secagem é realizada. Têm-se como características distintas entre os processos: - A Quente: maior consumo de gás; forte degradação do refratário; temperatura de trabalho do distribuidor mais elevada, deteriorando as condições do ambiente; - A Frio: menor consumo de gás; redução da degradação do refratário; no entanto, exige um controle rigoroso da curva de secagem, o que implica maior investimento inicial no equipamento de secagem. Em 2002, após uma análise de viabilidades a ArcelorMittal Tubarão implementou o sistema de frio. Este artigo mostra a evolução deste sistema após a sua implementação, analisando a correlação com defeitos, a implementação de melhorias e os ganhos obtidos.

Palavras-chave: Distribuidor; Aquecimento; Partida a frio e a quente.

\section{EVOLUTION IN THE COLD TUNDISH SYSTEM IN THE CONTINUOUS CASTING PROCESS AT ARCELORMITTAL TUBARÃO}

\begin{abstract}
In the Continuous Casting Process it is necessary drying and/or preheating the tundish. This is performed I order to reduce the heat loss of the liquid steel and it implies in the following benefits: preventing freezing in the tundish; preventing bubbles in the first slabs; to avoid internal reactions in the liquid steel inside tundish caused by moisture and also preventing refractory degradation caused by thermal shock. Conventionally, when casting flat products (slabs), the system to promote drying r preheating can be "hot" o "cold". It is called "hot start system" when drying and preheating is performed in the tundish and "cold start system", when only drying is performed. The main differences between the cold and hot procedures are: -Hot Procedure: Higher gas consumption; stronger degradation of the refractory; increasing the temperature in the ladle platform, affecting the environment condition for workers in this region; - Cold Procedure: Reduced gas consumption; lower refractory consumption; improved working conditions, however, it requires strictly control of the drying curve and, therefore, a greater initial investment in the drying equipment. AcelorMittal Tubarão implemented, in 2002, the cold system after a feasibility analysis. This paper shows the evolution of the system after its implementation.

Keywords: Tundish; Preheating; Drying; Cold start system; Hot start system.

1 Mestre em Metalurgia, Físico, Especialista de Lingotamento Contínuo, ArcelorMittal Tubarão, Membro da ABM, Serra, ES, Brasil.

2 Mestre em Administração, Engenheiro Metalúrgico, Gerente Geral de Placas e Bobinas, ArcelorMittal Tubarão, Serra, ES, Brasil.

3 Engenheiro Metalúrgico, Gerente de Confiabilidade de Produção de Placas, ArcelorMittal Tubarão, Serra, ES, Brasil.

4 Mestre em Metalurgia e Engenharia de Materiais, Gerente de Lingotamento Contínuo, ArcelorMittal Tubarão. Serra, ES, Brasil.

5 Administrador de Empresas, Supervisor de Sincronismo da Produção da Aciaria, ArcelorMittal Tubarão. Serra, ES, Brasil

6 Engenharia de Materiais, supervisor de Refratários, Reframax. Serra, ES, Brasil.
\end{abstract}

* Contribuição técnica ao $45^{\circ}$ Seminário de Aciaria - Internacional, 25 a 28 de maio de 2014, Porto Alegre, RS, Brasil. 


\section{INTRODUÇÃO}

Genericamente, o distribuidor de uma máquina de lingotamento é um vasilhame revestido internamente com refratário que tem como funções básicas: distribuir o aço nos veios, atuar como reservatório de aço durante o tempo de troca de panela e promover a flotação de inclusões não metálicas. No lingotamento contínuo de aços planos que utilizam distribuidores que comportam volumes de aço líquido superiores a 45 toneladas, a condição térmica do refratário, sempre foi um ponto de extrema importância. Diferentemente das siderúrgicas de longos cuja capacidade dos distribuidores é geralmente menor, a tendência que imperou nas siderúrgicas de produtos planos, para garantir a condição térmica dos distribuidores antes da partida, foi o pré-aquecimento do mesmo à temperaturas superiores a $1000^{\circ} \mathrm{C}$. Acreditava-se teoricamente que efetuando o pré-aquecimento reduzir-se-ia o risco de reações internas em função do hidrogênio retido na massa de revestimento, o congelamento da primeira porção de aço vazada da panela para o distribuidor, a formação de bolhas nas primeiras placas e a degradação do refratário pelo choque térmico. Esta prática prevaleceu também na ArcelorMittal Tubarão até meados de 2000, quando iniciou-se o desenvolvimento do processo de partida de máquina com distribuidores somente secos, ou denominados "partida a frio". Neste processo o objetivo não é elevar a temperatura do revestimento refratário a valores maiores que $1000^{\circ} \mathrm{C}$, mas sim, garantir a retirada da umidade do revestimento refratário a patamares inferiores a $0,5 \%$.

A implantação deste sistema (em Tubarão), conforme descrito por Andrade [1], após investimentos e ajustes nos sistemas de secagem de distribuidor, aquecimento do canal de alimentação distribuidor-molde foi realizada com sucesso em 2002 na siderúrgica de Tubarão, trazendo como principais benefícios: redução de $70 \%$ no tempo de retorno de máquina após interrupções no início de sequência; redução de $78 \%$ no consumo de gás combustível; aumento de $90 \%$ na vida das tampas de distribuidores; melhora nas condições de trabalho na plataforma de lingotamento, motivado pela redução de ruído e calor.

Todavia, com o aumento da capacidade produtiva de Tubarão, a oscilação e a entrada em mercados de aços mais elaborados, como os aços ultra baixo carbono para indústria automobilística, como também as alterações no modelo de fornecimento refratário dos distribuidores, as mudanças nos padrões térmicos de liberação de panelas da área de Refino para o Contínuo, a purga de argônio antes do distribuidor; o sistema de partida a frio foi questionado sobre a sua eficiência efetiva diante destas novas condições de trabalho.

\subsection{Objetivo}

O objetivo deste trabalho é mostrar as respostas aos principais questionamentos feitos ao sistema de partida a frio após a sua implantação e a evolução deste para se adequar a nova realidade produtiva.

\subsection{Revisão da Literatura}

Revisitando os estudos promovidos por Andrade [1], sobre partida a frio, este menciona alguns paradigmas que foram quebrados para a efetivação desta nova filosofia de trabalho em Tubarão. Destacam-se: o receio da perda térmica; a permanência de umidade no revestimento refratário e a maior degradação do

\footnotetext{
* Contribuição técnica ao 450 Seminário de Aciaria - Internacional, 25 a 28 de maio de 2014 Porto Alegre, RS, Brasil.
} 
refratário. Entretanto, resíduos destes paradigmas permaneceram, e no decorrer do tempo após a implantação do sistema de partida a frio, diante de ocorrências não desejadas, principalmente relacionadas a qualidade das placas, estes novamente afloraram, questionando os benefícios da partida a frio.

Para responder a estes questionamentos foi necessário buscar uma literatura específica, como a vasta pesquisa realizada por Junior [2], quando da ocorrência de uma crise do defeito esfoliação (sliver) nas bobinas de Tubarão, onde durante a exploração das variáveis de limpidez do aço chegou-se até interromper a utilização do Sistema de Partida a Frio, até que fossem caracterizadas as inclusões e as correlações existentes. A Figura 1 mostra a diversidade de mecanismos de aprisionamento de inclusões na frente de solidificação no molde, cuja origem pode ser de diversas fontes como: o próprio refino do aço, refratário de panela, distribuidor, fluxante, etc.

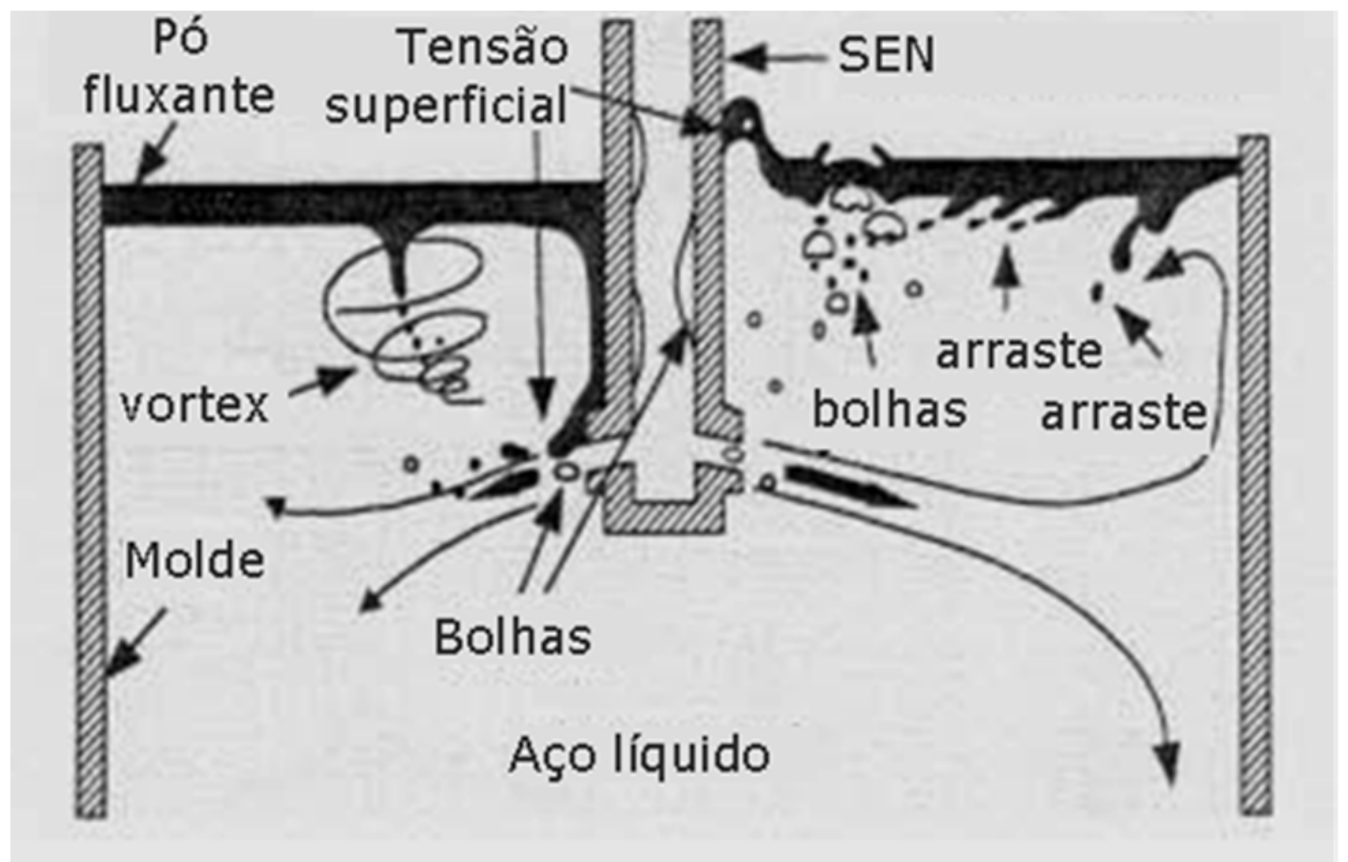

Figura 1. Mecanismos de aprisionamento de inclusões no molde.

A conexão da influencia da partida a frio com este defeito, baseou-se preliminarmente na possibilidade de uma maior degradação do refratário, cujas inclusões poderiam migrar para o molde e serem aprisionadas pela frente de solidificação. Mas, como a abrangência do questionamento sobre o sistema de partida a frio partindo do defeito esfoliação apresenta-se dentro de um campo de interações bastante amplo, outras questões foram levantadas. Concomitantemente, também foi analisada a questão da partida com distribuidor a frio versus a influência térmica na partida dos veios, em função das oscilações de produção. Estas análises deram-se a partir dos estudos teóricos e experimentais sobre o congelamento no início do lingotamento (distribuidor-molde), efetuados por Morais [3].

Buscou-se nas simulações computacionais realizadas por Morais [3] e Thomas [4], interpretar qual seria a real parcela da condição térmica da partida à temperatura ambiente, no complexo fenômeno da extração de calor que se dá através das diferentes formas de transferência. Dentro deste contexto, Garcia [5] descreve que o fenômeno de solidificação dos metais apresenta fundamentalmente dois aspectos: um aspecto metalúrgico ligado à composição química do metal e um aspecto térmico

* Contribuição técnica ao 45 Seminário de Aciaria - Internacional, 25 a 28 de maio de 2014, Porto Alegre, RS, Brasil. 
relativo à história térmica anterior do metal, ao modo pelo qual o calor é transferido e à distribuição de temperatura a cada instante do processo em regime transiente.

Diante destes questionamentos sobre a partida a frio, e do fato da bibliografia existente, apesar de cobrir pontos importantes, não ser plenamente capaz de explica-los, definiu-se métodos experimentais e de checagem para aprimoramento desta prática, cujos benefícios são de grande importância dentro do atual conceito de sustentabilidade industrial.

\section{MATERIAL E MÉTODOS}

\subsection{Avaliação da Influência da Partida a Frio nos Questionamentos Referentes} as Defeitos Esfoliação, Inclusões, Bolhas, Concomitantemente com a Perda Térmica.

Apesar dos resultados das pesquisas de Junior [2] não indicarem que a variável partida a frio mantinha conexão importante com o defeito esfoliação. Estes indicaram outras com relevância muito mais significativa, como baixas velocidades de lingotamento, reoxidação nas conexões refratarias,... (Figuras $2 a$ e $2 b$ ); o receio em relação da partida a frio persistiu.

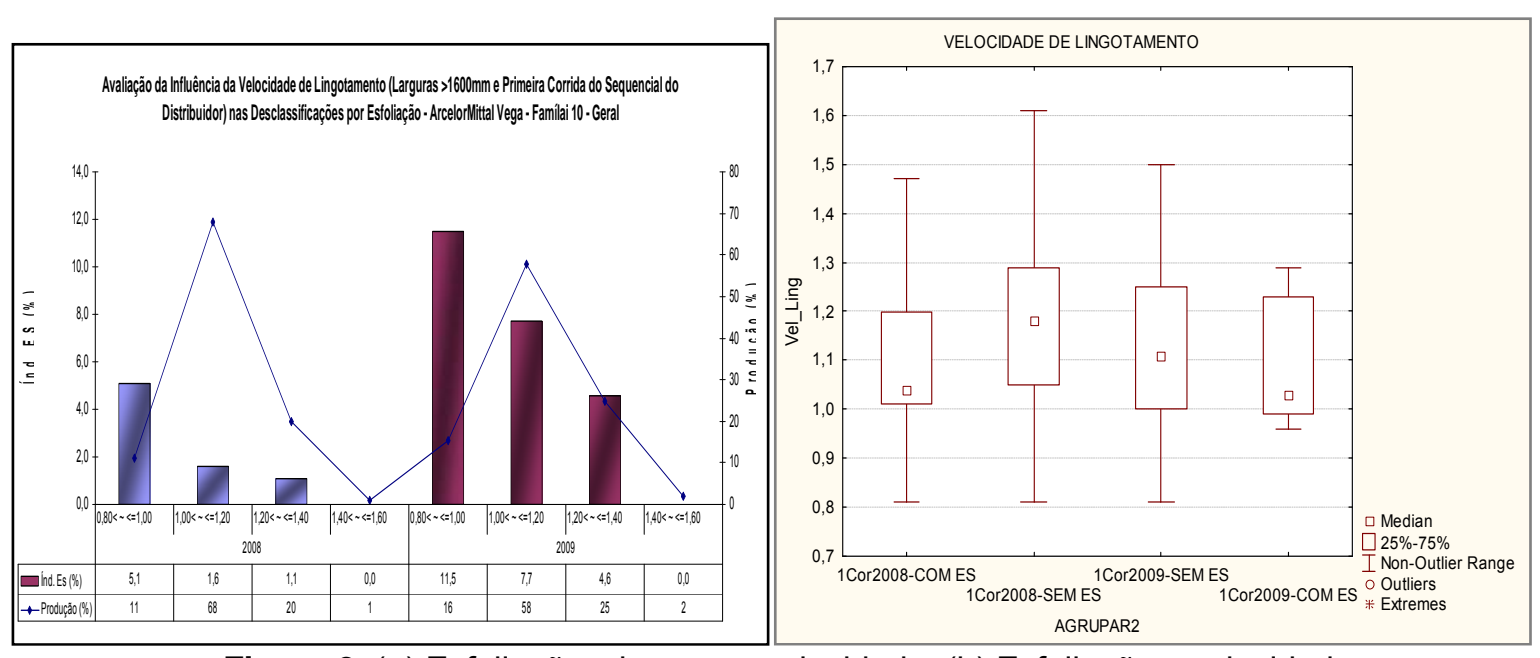

Figura 2. (a) Exfoliação x largura e velocidade; (b) Esfoliação x velocidade.

Visando dissipar a suspeita ainda remanescente sobre a partida a frio, elaborou-se um plano experimental dentro da metodologia Seis Sigma - Dimac [6], para avaliar a real influencia da partida a frio no defeito esfoliação.

$\mathrm{Na}$ fase inicial, definiu-se através de um diagrama de causa e efeito, algumas possibilidades desta influência (Figura 3).

* Contribuição técnica ao 45 Seminário de Aciaria - Internacional, 25 a 28 de maio de 2014, Porto Alegre, RS, Brasil. 

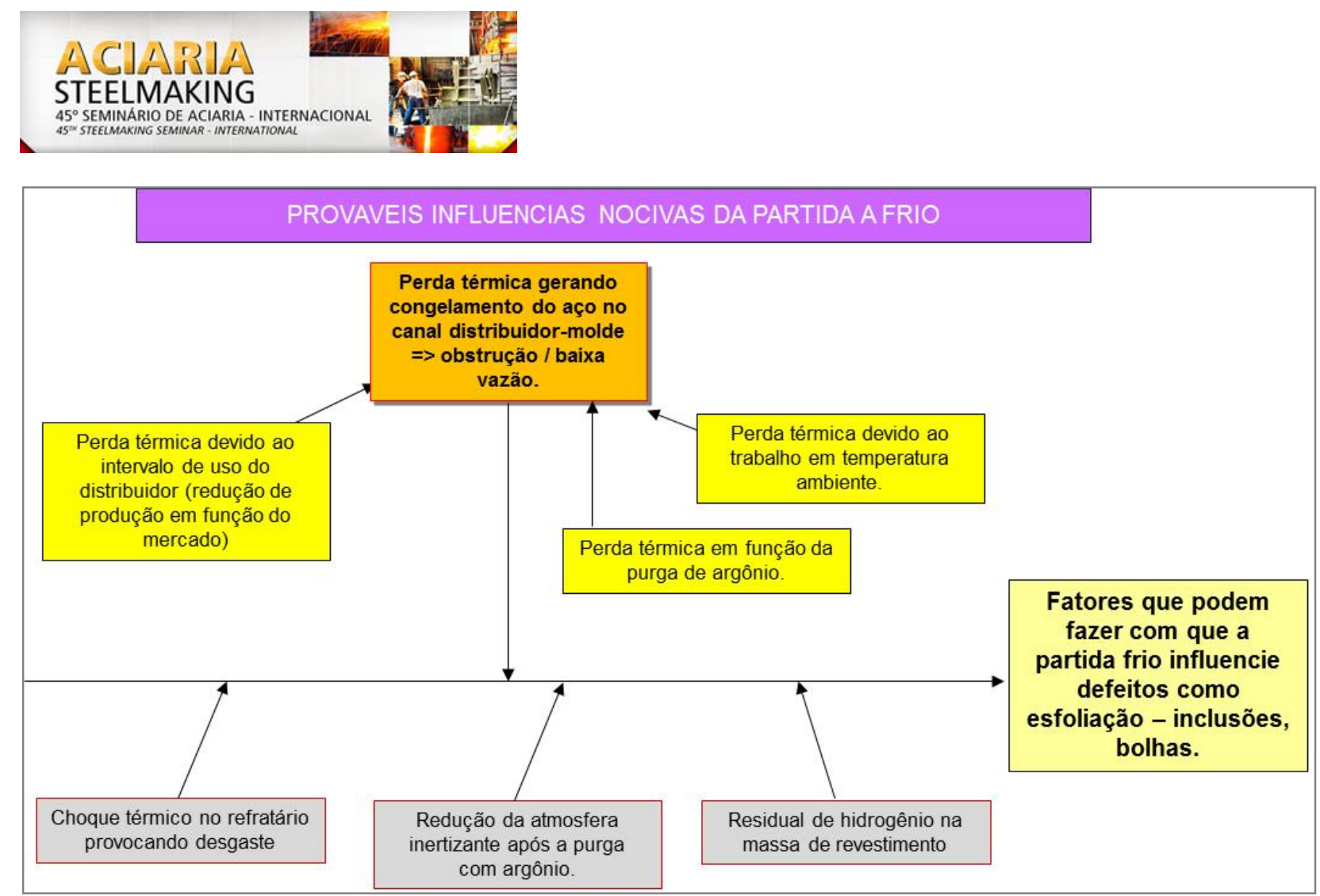

Figura 3. Diagrama com potenciais influências nocivas do sistema de partida a frio.

As avaliações das potenciais causas de influencias nocivas do sistema de partida a frio foram realizadas a partir de medições "in loco" do percentual de umidade, da concentração de oxigênio após purga com argônio, da temperatura superficial do revestimento refratário, da temperatura da primeira porção de aço líquido dentro do distribuidor e da inspeção visual das condições do revestimento refratário. Importante ressaltar também que a base metodológica foi sempre a comparação entre os distribuidores que partiram a frio e os que partiram a quente. $O$ número de partidas comparadas obedeceu ao critério de amostragem finita descrito por Triola [7].

\subsubsection{Método para avaliação da perda térmica}

No caso da avaliação da perda térmica, desenvolveu-se preliminarmente um dispositivo específico para medir a temperatura da primeira porção de aço líquido vazada da panela para o distribuidor (Figura 4); quando ainda não se contava com o sistema de medição Castemp ${ }^{\circledR}$.

O dispositivo ilustrado na Figura 4, era composto por três lanças com termopares especiais do tipo "S - PtRh10\%/PtRh6\%" com baixa emissão de f.e.m para tornarse mais sensível a coleta de temperatura na região pesquisada - faixa de temperatura de 0 a $1700^{\circ} \mathrm{C}$ (calibrados previamente) conectados por cabos termicamente resistentes, sem necessidade de compensação, ao instrumento de coleta de dados. O mesmo foi devidamente ajustado para medir a temperatura do aço em 3 níveis a partir do fundo do distribuidor: 150mm (5t); 400mm (11t) e $600 \mathrm{~mm}(20 \mathrm{t})$, e foi de fundamental importância para a comparação da perda térmica entre os distribuidores de partida a quente e de partida a frio.

* Contribuição técnica ao 450 Seminário de Aciaria - Internacional, 25 a 28 de maio de 2014, Porto Alegre, RS, Brasil. 

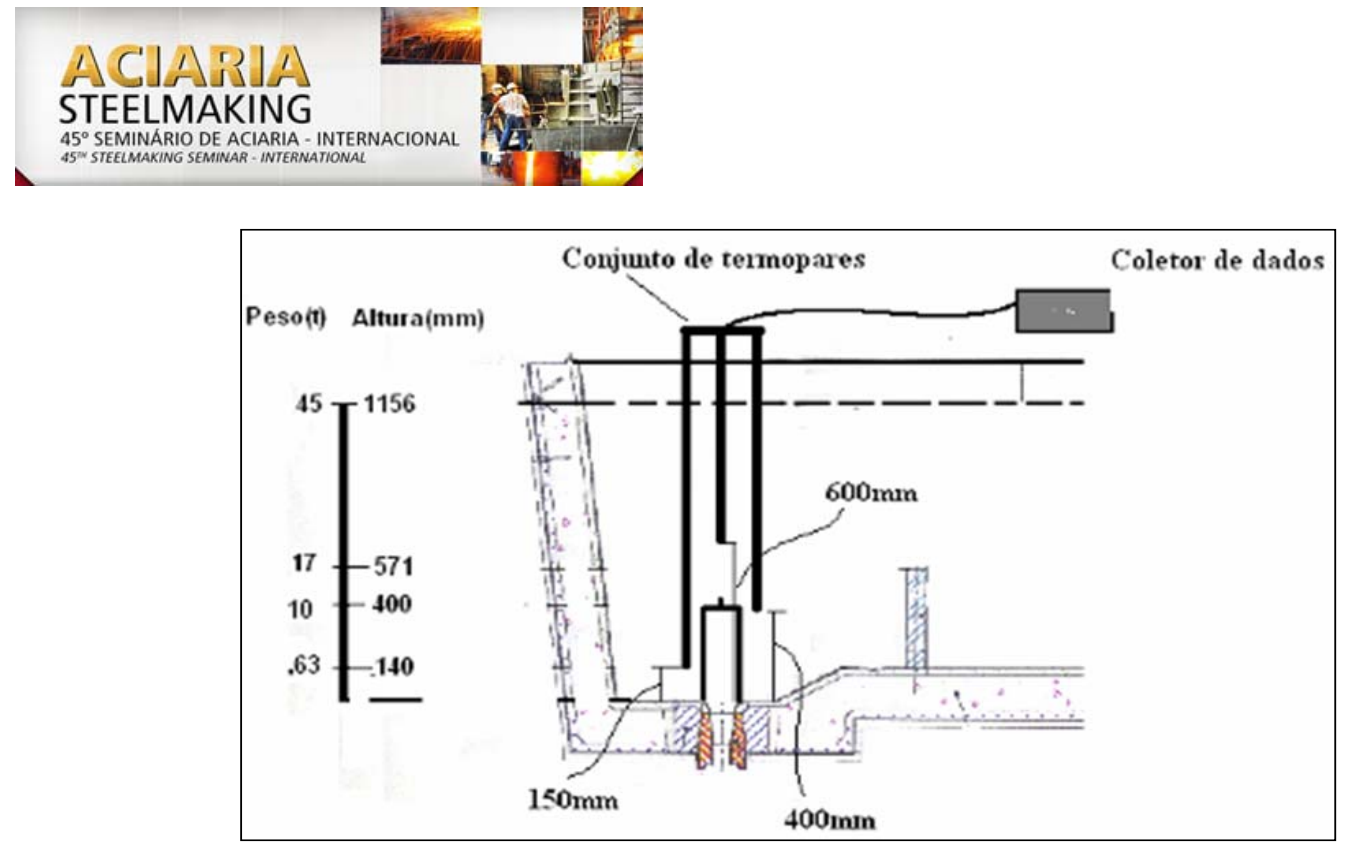

Figura 4. Sistema para medição da temperatura da primeira porção de aço no distribuidor.

Os dados coletados foram avaliados e confrontados com resultados apurados na implantação do projeto por Andrade [1], onde o processo amparou-se na medição da temperatura na superfície refratária antes do vazamento de aço líquido (termopares inseridos na carcaça do distribuidor) e da medição discreta de temperatura após 6 minutos da abertura da panela. As análises relativas são apresentadas nos capítulos de Resultados e Discussões.

\subsubsection{Método de avaliação da temperatura da superfície refratária}

A medição da temperatura superficial do revestimento refratário foi realizada apenas como uma ação paralela e secundária à medição da perda térmica. A mesma foi realizada através de pirômetros a laser (devidamente calibrados) dentro de intervalos de tempo e distâncias pré-estabelecidas.

\subsubsection{Método de verificação da concentração de oxigênio após purga com argônio}

A concentração de oxigênio após purga de argônio no distribuidor (realizada instantes antes do vazamento de aço líquido) foi realizada através de um Analisador Portátil de Concentração de Oxigênio tipo Célula Paramagnética. Considerou-se como uma purga de argônio eficiente, quando se encontrou valores residuais de oxigênio no distribuidor $\leq 5 \%$, e a comparação foi realizada entre os distribuidores que partiram a frio e os que partiram a quente.

\subsubsection{Método de avaliação do teor de umidade}

O percentual de umidade foi medido basicamente dentro do mesmo formato realizado por Andrade [1], onde avaliou-se a eficiência da secagem medindo a umidade residual dos distribuidores, cujos valores não podem ultrapassar $1 \%$. Os pontos de medição do teor de umidade no revestimento refratário do distribuidor obedeceram ao esquema mostrado na Figura 5 abaixo.

\footnotetext{
* Contribuição técnica ao 450 Seminário de Aciaria - Internacional, 25 a 28 de maio de 2014, Porto Alegre, RS, Brasil.
} 


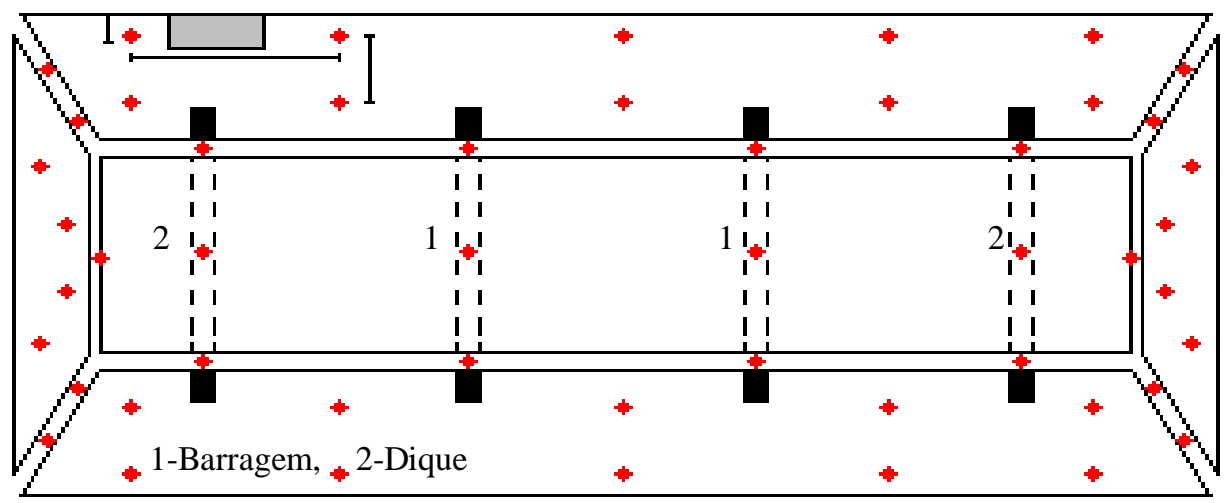

Figura 5. Pontos de Medição de Umidade.

Também em relação à umidade, avaliou-se o "pick up" de hidrogênio, cuja mensuração do teor de hidrogênio foi efetuada através do Sistema Hydris ${ }^{\circledR}$. Buscouse conhecer o comportamento dos distribuidores a frio e quente na geração do hidrogênio durante o seu enchimento e ao longo de todo o ciclo de lingotamento.

\section{RESULTADOS}

As análises realizadas no Capítulo 2 (acima), não mostraram efeitos nocivos relativos ao sistema de partida com distribuidores a frio. Resume-se a seguir os principais resultados.

Especificamente sobre a influência da partida a frio no defeito esfoliação os resultados experimentais comparativos não indicaram nenhuma tendência de aumento deste defeito quando se usa o sistema a frio. Considerou-se para avaliação da qualidade as primeiras corridas dos distribuidores e os resultados de esfoliação alcançados em Vega, pois estas representam as melhores condições para avaliação do impacto na qualidade relacionado aos testes com partidas a frio do distribuidor. Historicamente, a primeira corrida do distribuidor apresenta pior índice de esfoliação em Vega e as esfoliações em Vega são principalmente originárias da alumina. Praticamente, não se encontrou variação dos percentuais de esfoliação nas primeiras corridas entre os sistemas de partida a frio e quente. Os resultados apresentados não impõe restrições ao uso de distribuidores a frio. A tabela da Figura 6 mostra os resultados de qualidade de bobina na inspeção do Parsytech.

\begin{tabular}{|c|c|c|c|c|c|c|}
\hline \multirow{2}{*}{ MLC\# } & \multirow{2}{*}{ EVQ } & \multicolumn{2}{|c|}{ Partida a Quente } & \multicolumn{2}{|c|}{ Partida a Frio } & \multirow{2}{*}{ Teste Hipótese (P1: Partida a Frio / P2: Partida a Quente) } \\
\hline & & \%ES & $\mathrm{N}^{\circ} \mathrm{BQs}$ & \%ES & $\mathrm{N}^{\circ} \mathrm{BQs}$ & \\
\hline \multirow{2}{*}{2} & Geral & $43.3 \%$ & 379 & $37.2 \%$ & 86 & $\begin{array}{c}\text { Teste Q2 : Hipótese de mesma populaçäo aceita, valor limite }=3.84 \text {; } \\
\text { Q2 }=1.057 \text { (Pvalue }=0.304) ; \text { Nivel de confiança } 95 \% ; P 1: 37.21 \% \text { e } \\
\text { P2: } 43.27 \% \text {; Teste } Z \text { : Hipótese de mesma populaçäo aceita, valor } \\
\text { limite }=|1.96| ; \text { valor } Z=1.03 \text { (Pvalue }=0.152 \text { ) ; Nivel de confiança de } \\
95 \% ; P 1: 37.21 \% \text { e P2: } 43.27 \%\end{array}$ \\
\hline & $\begin{array}{l}\text { Sem } \\
\text { EVQs } \\
\text { Críticos }\end{array}$ & $40.4 \%$ & 218 & $37.3 \%$ & 51 & $\begin{array}{c}\text { Teste Q2 : Hipótese de mesma populaçäo aceita, valor limite }=3.84 \text {; } \\
\text { Q2 }=0.167 \text { (Pvalue }=0.683 \text { ) ; Nivel de confiança } 95 \% ; P 1: 37.25 \% \text { e } \\
\text { P2: } 40.37 \% \text {; Teste } Z \text { : Hipótese de mesma populaçäo aceita, valor } \\
\text { limite }=|1.96| \text {; valor } Z=0.41 \text { (Pvalue }=0.341 \text { ) Nivel de confiança de } \\
95 \% ; P 1: 37.25 \% \text { e P2: } 40.37 \%\end{array}$ \\
\hline
\end{tabular}

Figura 6. Resultados de esfoliação no aço UBC Parte Não Exposta no Parsytec.

* Contribuição técnica ao 450 Seminário de Aciaria - Internacional, 25 a 28 de maio de 2014, Porto Alegre, RS, Brasil. 
Verifica-se que a esfoliação na inspeção do Parsytec (referência: material Ultra Baixo Carbono Não Exposto - padrão AAC012D230), nas primeiras corridas do distribuidor lingotadas com partida a frio apresentaram resultados de ocorrência de esfoliação similares ou melhores aos das corridas com partida a quente.

Analisando também a esfoliação quanto ao status de classificação/desclassificação no LTQ e LTF/VEGA Tubarão, constata-se que não ocorreu desclassificação, conforme mostram as tabelas das Figuras $7 \mathrm{a}$ e $7 \mathrm{~b}$.

\begin{tabular}{|c|c|c|c|c|c|}
\hline \multirow{2}{*}{ MLC\# } & \multirow{2}{*}{ EVQ } & \multicolumn{2}{|c|}{ Partida Q Quente } & \multicolumn{2}{c|}{ Partida a Frio } \\
\cline { 2 - 6 } & & $\%$ ES & Prod. (t) & $\%$ PS & Prod. (t) \\
\hline \multirow{2}{*}{2} & Geral & $0.95 \%$ & 10.562 & $0 \%$ & 2.367 \\
\cline { 2 - 6 } & Sem EVQs Críticos & $0 \%$ & 6.100 & $0 \%$ & 1.366 \\
\hline
\end{tabular}

\begin{tabular}{|c|c|c|c|c|}
\hline \multirow{2}{*}{ Produtos - AM Vega } & \multicolumn{2}{|c|}{ Partida a Quente } & \multicolumn{2}{c|}{ Partida a Frio } \\
\cline { 2 - 4 } & $\%$ PS & Prod. (t) & $\%$ ES & Prod. (t) \\
\hline Galvanizada Extragal - GI - X & $0 \%$ & 4.798 & $0 \%$ & 850 \\
\hline Galvanizada Galvallia - GA - X & $0 \%$ & 747 & $0 \%$ & 302 \\
\hline Galvanizada Galvalume - GL - X & $0 \%$ & 20 & - & - \\
\hline Laminada a Frio - X & $0 \%$ & 3.744 & $0 \%$ & 434 \\
\hline Total Geral & $0.37 \%$ & 9.310 & $0 \%$ & 1.586 \\
\hline
\end{tabular}

Figura 7. (a) Resultados de esfoliação no aço UBC Parte Não Exposta - LTQ-Tubarão; (b) Resultados de esfoliação no aço UBC Parte Não Exposta - LTF VEGA-Tubarão.

Os resultados da perda térmica mostraram que realmente a partida a frio, apesar do aquecimento do canal de alimentação de aço líquido distribuidor-molde, é um pouco maior que a da partida a quente. Entretanto, a compensação térmica já prevista nos padrões de liberação de temperatura de panela da Área de Refino para o Contínuo, contemplam plenamente este diferença térmica, que hoje se encontra na faixa entre 4 a $9^{\circ} \mathrm{C}$. A Figura 8 ilustra o delta de temperatura nos primeiros 15 minutos de lingotamento entre os sistemas de partida a frio e a quente.

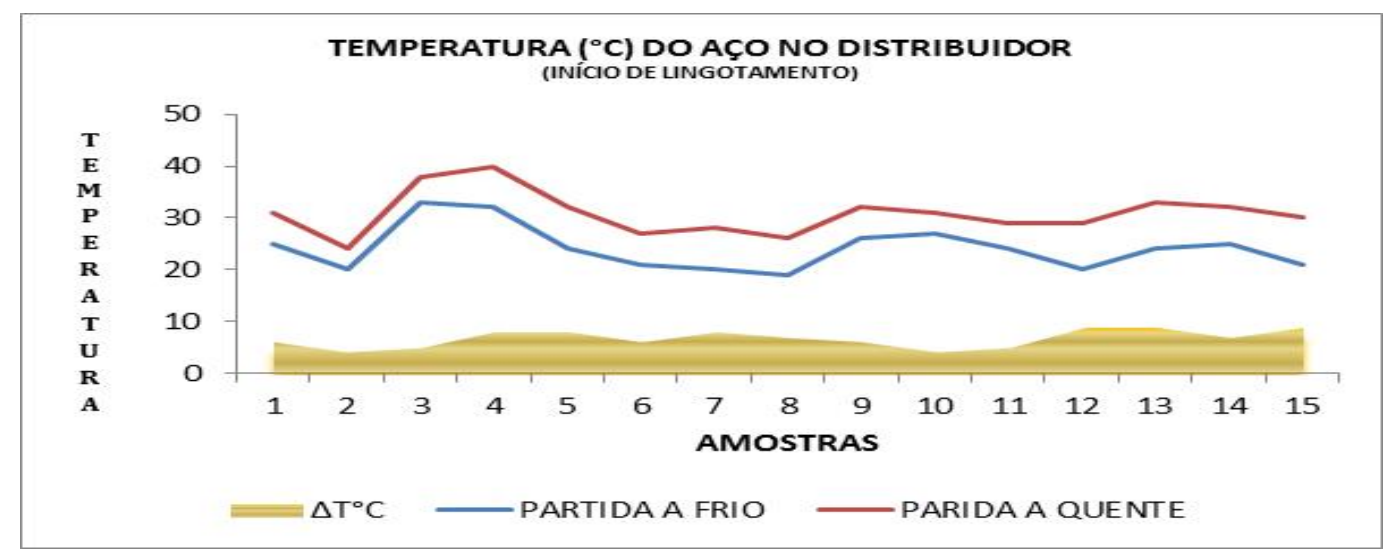

Figura 8. Gráfico: $\Delta \mathrm{T}^{\circ} \mathrm{C}$ entre distribuidores a frio e a quente.

Quanto aos teores residuais de oxigênio após a purga com argônio, o gráfico da Figura 9, mostra resultados mais favoráveis para o sistema de partida a frio.

* Contribuição técnica ao 450 Seminário de Aciaria - Internacional, 25 a 28 de maio de 2014, Porto Alegre, RS, Brasil. 

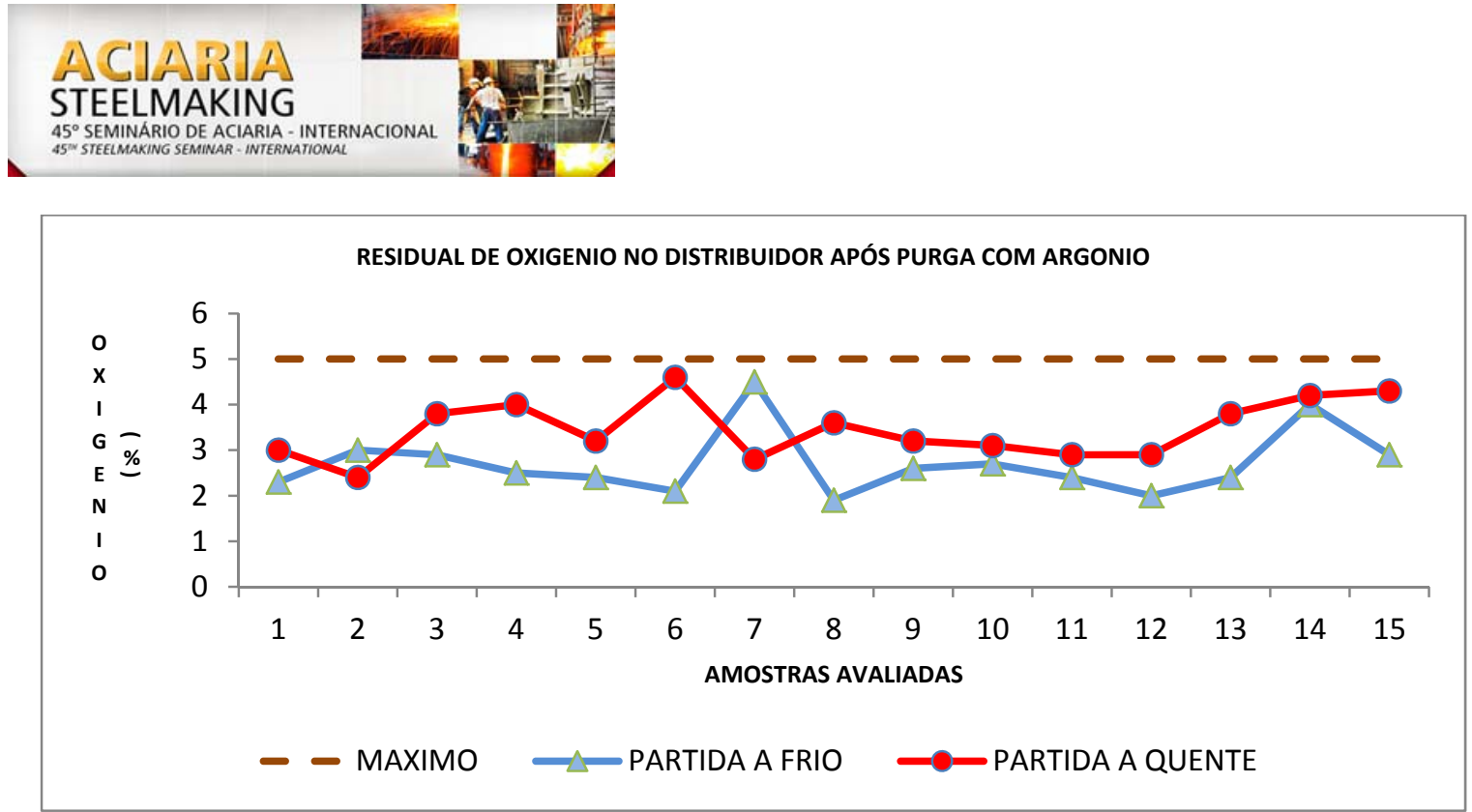

Figura 9. Gráfico: Teor residual de oxigênio após purga.

No que tange aos resultados referentes ao percentual residual de umidade no distribuidor, bem como ao teor de hidrogênio no aço, os resultados também foram dentro do esperado.

No caso da umidade no revestimento refratário do distribuidor, em nenhuma das amostragens, dentro de um intervalo após secagem de até 30 horas, o percentual não ultrapassou a $0,58 \%$, e até 40 horas o valor máximo encontrado foi $0,88 \%$, ou seja, ambos abaixo do limite de $1 \%$, que é o valor de referência para iniciar condições de restrições ao processo a frio.

Já o teor de hidrogênio no aço líquido apresentou resultados similares entre as partidas realizadas a frio e a quente, conforme se vê no gráfico da Figura 10 . Os valores de hidrogênio incorporado ao aço, apenas são relevantes no início de enchimento do distribuidor, este valor fica em torno de 1,9 ppm, e a estabilização do teor de hidrogênio incorporado ao aço se dá muito rápido, ou seja, a incorporação do hidrogênio é menor que $1 \mathrm{ppm}$ a partir de 50 toneladas vazadas, e menor que $0,5 \mathrm{ppm}$ antes do vazamento de 75 toneladas. Apresenta, portanto o mesmo comportamento da partida a quente, o que conduz à afirmativa que o "pick up de hidrogênio" oriundo do distribuidor de partida a frio não é um ponto de preocupação. Ressalta-se que a partir de 150 toneladas em ambos os sistemas o teor de hidrogênio já não apresenta relevância.



Figura 10. Gráfico: Teor de hidrogênio em PPM ao longo do lingotamento.

A inspeção visual nos distribuidores de partida a frio e a quente mostraram que a degradação refratária nos distribuidores de partida a quente é muito maior em relação aos de partida frio; principalmente, em função da erosão das tampas refratárias durante o processo de pré-aquecimento do distribuidor. (Figura 11).

* Contribuição técnica ao 45 Seminário de Aciaria - Internacional, 25 a 28 de maio de 2014, Porto Alegre, RS, Brasil. 

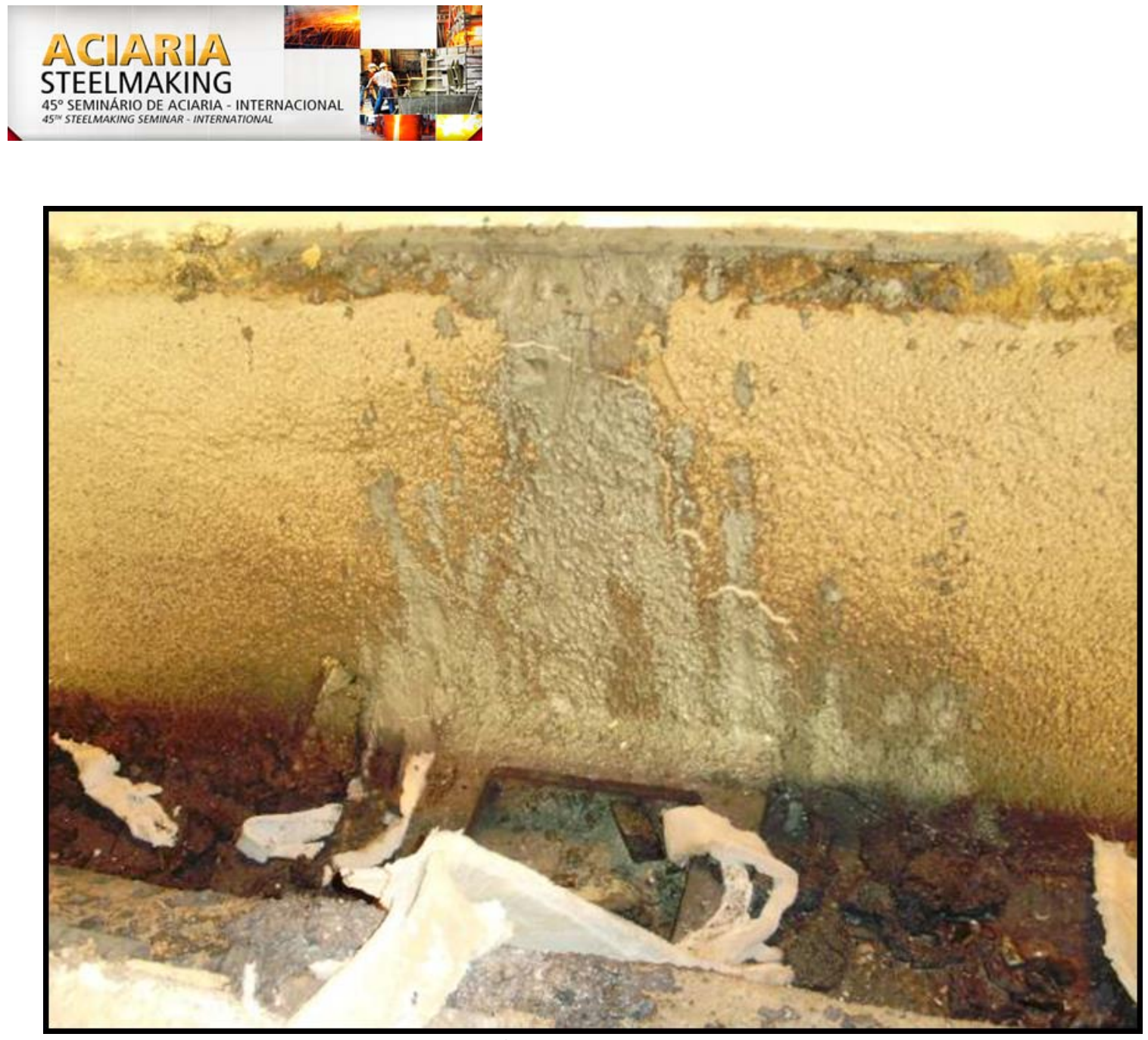

Figura 11. Degradação refratária detectada após pré-aquecimentos.

\section{DISCUSSÃO}

Os resultados obtidos mostram que mesmo após as alterações do mix produtivo de Tubarão, as oscilações de volume de produção em função das condições de mercado, o sistema de partida com distribuidores a frio não é nocivo ao processo, nem à qualidade do produto. Todavia, vale discutir alguns pontos importantes sobre os resultados.

No caso da perda térmica, a diferença de temperatura principalmente entre a primeira porção de aço que entra em um distribuidor proveniente de uma partida a quente, em relação a um de partida a frio, deve ser sempre considerada dentro de uma margem de segurança, para que esta jamais seja contribuição ao congelamento do aço na partida. Extremamente importante deve ser a atenção dispensada a dois aspectos no caso da partida a frio: o primeiro é ao aquecimento do canal distribuidor-molde, pois, o não cumprimento rigoroso dos padrões térmicos relativos é nefasto; o segundo é quanto a alterações no mix de produção que impliquem em alterações das curvas de "superheat" baseadas nas equações de temperatura liquidus. Estes dois aspectos são fundamentais para a garantia de uma partida eficiente, e, portanto, devem sempre ser auditados e mantidos sobre rigoroso controle.

Nos resultados referentes ao defeito "esfoliação" faz-se importante ressaltar que apesar de não haver se encontrado nenhuma conexão direta com a partida a frio, em função da rigorosa aplicação do material a ser utilizado em partes expostas dos veículos, ainda mantém-se um plano experimental de acompanhamento.

* Contribuição técnica ao 450 Seminário de Aciaria - Internacional, 25 a 28 de maio de 2014, Porto Alegre, RS, Brasil. 
Já em relação a umidade um aspecto que não pode deixar de ser discutido é o limite de utilização após a secagem. Na determinação deste limite, fundamental é a verificação da absorção da umidade em função do tempo. Deve-se sempre considerar: umidade relativa do ar, condição de projeção do refratário de trabalho, curva padrão de secagem e condições operacionais do distribuidor.

Outra discussão que não pode deixar de ser explicitada é a relativa aos aços com restrições ao teor de hidrogênio. Apesar dos resultados dos teores de hidrogênio serem similares em ambos os sistemas (a frio e a quente), por extrema prudência no sentido de não se imputar uma mínima contribuição no teor de hidrogênio, mantemse a opção de produzir os aços com tais restrições pelo sistema a quente. Este é com certeza um paradigma ainda a ser quebrado.

Mas, não se pode encerrar a discussão sobre a partida a frio, sem deixar ressaltar os ganhos que a mesma apresenta na parte ambiental. Apesar da evolução tecnológica dos pré-aquecedores estes ainda consomem considerados volumes de gases, impõem um volume de ruído considerável na plataforma de lingotamento, e a carga térmica absorvida pela área operacional de trabalho próxima aos distribuidores é considerável. Tais aspectos são extremamente relevantes dentro do conceito de trabalho atual onde a sustentabilidade, a busca de um melhor ambiente de trabalho são constantes.

\section{CONCLUSÃO}

Os estudos apresentados mostraram que não há porque impor restrições ao sistema de partida com distribuidores a frio, e que os questionamentos ainda feitos não possuem sustentação científica, desde que obedecidos os padrões de utilização previstos. Evidentemente, que se deve atentar continuamente para a evolução do mix produtivo, bem como à renovação tecnológica dos equipamentos utilizados.

\section{Agradecimentos}

Os autores agradecem a todos que contribuíram direta e indiretamente na elaboração deste trabalho, em especial às equipes de manutenção refratária, elétrica e mecânica.

\section{REFERÊNCIAS}

1 Andrade Kb, Moreira DB, Duarte JC, Matos MF, Nascimento ZD. Implementatation of Cold Tundish at CST Continuous Casting Process. In: International Steelmaking Conference; abr. 2003. Association Technique de La Siderurgie Francaise; 2003.

2 Souza Junior JA, OLIVEIRA JR. Evolução da esfoliação química no material laminado para aplicação automobilística na AM Tubarão-Vega. In: $42^{\circ}$ Seminário de Aciaria Internacional; 15-18 mai. 2011; Salvador, Brasil. São Paulo: ABM; 2011.

3 Morais AA. Estudo Fenomenológico do Mecanismo de Obstrução do Fluxo de aço do Distribuidor para o Molde no Início do Lingotamento Contínuo de Placas [dissertação de mestrado]. Ouro Preto: UFOP; set. 2006.

4 Thomas B. Computational tools for analysis of fluid flow in metal casting processes. Huntington: Special Metals; March 24, 2003.

5 Garcia A. Solidificação dos Metais [apostila do curso]. Campinas: Faculdade de Engenharia Mecânica, Unicamp; 1980.

6 Werkema C. Criando a cultura Seis Sigma. Nova Lima: Elsevier; 2004.

7 Triola MF. Introdução à estatística. $7^{a}$ ed. Rio de Janeiro: LTC; 1999.

\footnotetext{
* Contribuição técnica ao 45 Seminário de Aciaria - Internacional, 25 a 28 de maio de 2014 Porto Alegre, RS, Brasil.
} 